\title{
Rational use of blood: a study report on single unit transfusion
}

\author{
J. H.Vachhani $\cdot$ J. R. Joshi $\cdot$ V. M. Bhanvadia
}

Received: 18 March 2008 / Accepted: 19 April 2008

\begin{abstract}
Rational use of blood and minimise risks of blood transfusion have been repeatedly emphasized by WHO and various other experts. One of the measures is to discourage practice of single unit transfusion as it is avoidable in large majority of cases. The present study explores the data of such transfusions. A pilot study carried out during January 2000-December 2000 and then a follow up study is carried pout during January 2006-June 2007. During the pilot study done during 12 months a total of 10,0100 blood transfusions were given, out of which $55.1 \%$ were single unit transfusions. The preliminary results were presented in a regional conference and then a meeting and discussion with various clinical heads were arranged in January 2001. Then a follow up study is carried out from January 2006-June 2007 (18 months). It is found that a total of 12,248 blood transfusions are given during this spell, out of which $52.81 \%$ were single unit transfusions. Conclusion and some suggestions are offered to improve blood transfusion services and awareness in our country.
\end{abstract}

Keywords Single unit transfusion · Medical audit · Decision analysis

\footnotetext{
J. H.Vachhani · J. R. Joshi · V. M. Bhanvadia Dept.of Pathology, M.P.Shah Medical College \& G.G. Hospital, Jamnagar Gujarat, India

J. H. Vacchani $(\triangle)$

e-mail:
}

\section{Introduction}

WHO has been insisting on Global Blood Safety Initiatives. Guidelines are given to decrease the risks involved in transfusion of blood and blood products. One of the suggestions is to minimise the practice of single unit transfusion as and when possible. Considering these facts, a pilot study was carried out to evaluate the practice of single unit transfusion in our institute. The data were collected for the period January 2000-December 2000 (12 months) and were analysed. The same were presented to heads of various clinical departments with a request to minimise such practice, in January 2001.

\section{Material and methods}

The present study was carried out in Pathology department of Guru Gobindsingh General Hospital, Jamnagar, having multi-speciality facilities, run by state government. The pilot study was done from January 2000-December 2000 (12 months). The results were analysed and presented in a state conference held in January 2001, (vide Table 1A). The results were sent to all the heads of various clinical departments and to Medical Superintendent of the hospital, with a request to study and minimise practice of single unit transfusion as and when possible. The same was discussed in details in a teaching staff members' meeting. To study the effects of above mentioned efforts, a follow-up study is carried out from January 2006-June 2007 (18 months, vide Table 1B).

The aim of this study is not only to evaluate percentage of single unit transfusion but also to develop an awareness 
about careful decision and need for Medical Audit Committee to evaluate every case in right perspective.

\section{Results}

During the period from January-December 2000 (12 months) a pilot study was carried out. During this period a total of 10,100 blood transfusions were given, out of which $55.1 \%$ were single unit transfusions, excluding pediatric patients having congenital hemolytic anemias, as these patients need single unit transfusions at required intervals, so they were excluded. However, including those patients the single unit transfusions were found to be $73.1 \%$. (as shown in Table 1A). The results were discussed in the state conference held in January 2001. Then a meeting was held and the topic was discussed with heads of various clinical departments to develop awareness and minimize transfusion related risks. Now a follow up study is carried out to study the effect of the previous efforts and to grow awareness to minimize blood transfusion related risks. It is found in the follow up study that a total of 12,248 transfusions are given out of which the single unit transfusions are $52.81 \%$, excluding patients with congenital hemolytic anemia (and including those patients it is $72.18 \%$ ) as shown in Table 1B.

\section{Discussion}

It is observed that, the work load on blood banks, load on voluntary blood donors, and the risks involved with blood transfusion are all related to the decision of transfusion of blood or its components. The practice of single unit transfusion is largely avoidable and this amounts to more than fifty percent $(>50 \%$, excluding the pediatric patients with hemolytic anemias e.g. Thalassemia, etc.).
It is also observed that in spite of requests and meetings, there is no change in the trends of single unit transfusion practice. It is difficult to predict even the approximate incidence of a donor in window period. To day the incidence of AIDS has increased and so the risk of transfusion of blood from a donor in window period is also more. Similarly HBsAg positive, asymptomatic donor population in our country is around $1.6 \%$. There are $\mathrm{HBsAg}$ negative but anti $-\mathrm{HBc}$ antibody positive donors who are also infective [1]. Such screening is not done in every place in our country.

\section{Conclusions}

Thus, the risks involved in blood transfusion (such as transmission of infection, allergy and later on immunological problems) can cause more harm than benefit to the recipient. Moreover, the work load on blood banks and socio-moral load on voluntary blood donors can be minimised to more than $53.0 \%$ ! We have realized the need for (i) commitment and support from National and State Health Authorities for co-ordinated blood programmes and (ii) support by a legal frame work as correctly pointed out by Neelam Dhingra et al.(WHO) [2] We need regular, Active Medical Audit to study, discuss and resolution after 'Decision Analysis' to find out the rationale of decision of transfusion in each and every clinical situation, as emphasized by James P.A.B [3]. Consideration of blood less surgery [3] is also equally important as ability of different patients to tolerate degree of anemia is variable and associated disease (like cardiovascular disease) may further contribute the need for correct assessment and decision analysis in each case [4]. We strongly believe that considerable improvement and re-structuring in blood transfusion services is required in our country on priority basis.

Table 1 Clinical Departments (A) Pilot study (January-December 200012 months) (B) Follow-up study (January 2006-June 2007, 18 months)

\begin{tabular}{lccccc}
\hline & Single Unit $\%$ & Single Units & 2 Units & $>2$ Units & Tota $1 \%$ \\
\hline Gen. Medicine & 06.2 & 5.62 & 3.53 & 3.71 & 12.86 \\
Gen. Surgery & 12.0 & 8.42 & 4.38 & 2.18 & 14.98 \\
O \& G Dept. & 12.0 & 15.12 & 3.59 & 2.34 & 21.05 \\
Orthopedics & 11.9 & 09.71 & 2.24 & 0.51 & 12.46 \\
Pediatrics (a) & 04.4 & 10.17 & 1.98 & 0.61 & 12.76 \\
Pediatrics (b) & 18.0 & 19.37 & 1.53 & 0.19 & 21.09 \\
Others & 08.6 & 3.77 & 0.67 & 0.31 & 04.75 \\
Total (a) & 55.1 & 52.81 & 16.15 & 9.44 & 100.00 \\
Total (b) & 73.1 & 72.18 & 17.92 & 9.90 & \\
\hline
\end{tabular}

(a) = Patients except those having congenital hemolytic anemia.

(b) = Those with hemolytic anemia. 


\section{References}

1. Sudha Rangnathan, Iyer RN (2007) How close are we to Safe Blood transfusion-An insight into HBV infection. Ind Hematol Transfus 33(1\&2):29-31

2. Neelam Dhingra, Shan Lloyel, Jan Fordham et al (2003) World Health Organization. Activities for Blood Safety programme. Ind Hematol Transfus (suppl. III, sepcial issue) $1-5$

3. James P (2003) AuBuchon: An introduction to Decision Analysis. Ind Hematol Transfus 10-11

4. Jeffrey L Carson, Richard C Reynolds (2003) The Limits of bloodless surgery. Ind Hematol Transfus 98-100 